\title{
Study on Concept Connotation, Organization Characteristics and Practice Paths of Entrepreneurial University
}

\author{
Zhang Qingzhu, Li Zhiyi \\ Dalian University of Technology, Graduate School of Education, Dalian, Liaoning, China,116024
}

Keywords: entrepreneurial university; concept connotation; organization characteristics; practice path

\begin{abstract}
In order to meet the needs of social development, many colleges and universities began to move toward entrepreneurial orientation. Through research, it can be found that the development of university organizations will enter the development stage of entrepreneurial universities. This paper analyzes the connotation of entrepreneurial university, studies the characteristics of entrepreneurial university and puts forward the practical path for the construction of an entrepreneurial university in China.
\end{abstract}

\section{Introduction}

With the development of economy, the knowledge logic of the university is also changing. In the late 20th century, some research universities in the United States used their knowledge and technological research results to attract foreign investment in the development of new enterprises, accelerate the transformation of research results, and make contributions to the economic development of the country and the region. China introduced this practice in the late 1990s. Many Chinese universities are developing into entrepreneurial universities. Under such circumstances, the study of the characteristics and practice paths of entrepreneurial universities has an important role.

\section{Connotation Research of Entrepreneurial University}

At this stage, many experts and scholars at home and abroad think that entrepreneurial universities have two different research directions. One is to continue research along Burton Clarke. The theme of the study is that entrepreneurial universities are the problem of organizational transformation. That is, with the development of society, how colleges and universities use social development to carry out reforms, the object of researching is a college with all the spirit of reform and reform [1]. Burton Clarke researched Warwick University and Strathclyde University. In general, he believes that entrepreneurial universities refer to universities that are facing positive reforms in social development and have achieved certain results. In the course of this research, the research on the university mainly includes the external environment of the university, some problems encountered in the operation of the university, including the requirements of the government and society on the university, and the changes in the organizational structure of the university. Through this study, Burton Clarke believes that entrepreneurial universities have the following characteristics: a strong core driving force, a vast development periphery, a diversified financial basis, an active academic center, and a blended entrepreneurial culture. Burton Clarke's research is to regard the entire university as an organization main body and pays attention to how the university should conduct entrepreneurship and reform in order to adapt to social development.

The second method of research is Henry Ezkowicz's study. In this study, the main task is to study how the university can give full play to its advantages in knowledge creation and talent collection. The research subjects are research universities such as MIT and Stanford University. To study the social and economic conditions of these universities, transform the scientific research results of universities into productivity, make full use of the advantages of universities, and transfer knowledge. In this study, the purpose of entrepreneurial universities is to increase the economic strength of the country and the region. Entrepreneurial universities are not only important for the country's economic 
development but also change the university's functions and play an active role in activities.

In this study, the researchers mainly studied the following aspects: the relationship between the university and the government, the relationship between the university and the industry, the scientific research results and applications of the university, entrepreneurship courses, entrepreneur forums, entrepreneur networks, and other elements form a startup network. In this study, the characteristics of entrepreneurial universities are summarized as follows: conducting high-level research can quickly respond to national interests and national goals, play a unique role in universities, industries, and governments, participate in entrepreneurial activities, establish high-tech enterprises, and promote regional development. Economic development, Emphasis on cultivating students' innovation and entrepreneurship.

\section{Research on Organization Characteristics of Entrepreneurial University}

\subsection{Characteristics of organizational goals}

An important factor in differentiating social organizations is organizational goals. The core goal of an entrepreneurial university is to use knowledge. In his study of MIT, Zkowitz analyzed the role of MIT students in entrepreneurship and analyzed the logic of the reform process. The first university in China that explicitly proposed the establishment of an entrepreneurial university is Fuzhou University. University administrators believe: "Entrepreneurial universities emphasize the role of universities in social and economic development. Universities must not only impart knowledge but also develop students' entrepreneurial abilities. They must not only create knowledge and transform technology but also directly participate in and serve entrepreneurial activities." Therefore, Fuzhou University began to build an entrepreneurial university.

From the perspective of knowledge generation science, if the organizational goals of medieval universities are to spread cultural knowledge, then research universities will combine knowledge creation with universities. The organizational goal of entrepreneurial universities is to apply knowledge [2]. Therefore, the research of entrepreneurial universities is based on the concepts of knowledge transfer, academic entrepreneurship, and capitalization of knowledge. The main purpose of an entrepreneurial university is to use knowledge to promote economic development. Therefore, the organizational goal of an entrepreneurial university is to "raise the economic strength and level of the country and region."

\subsection{Characteristics of organizational elements}

The internal organizational structure of traditional teaching and research universities is very clear. In general, a university consists of two parts: academic units and administrative logistics service units. Academic institutions are based on knowledge classification and consist of various disciplines, professional and departmental composition. If these majors, colleges, and research institutions are considered to be an important part of traditional universities, then there are many organizational units in entrepreneurial universities that differ from traditional academic institutions. The more functions and boundaries of these units are not clear. University's organizational goals have an important role [3]. These organizational units are established by teachers, researchers and university students and are connected to the outside world, such as thematic forums, project centers, cooperation platforms and resource networks. We cannot simply determine whether this part of the organizational unit belongs to the university. It cannot simply be assumed that these organizational units do not belong to the university. Although the funding sources, organizational identities and working methods of these organizational structures are diversified, the common feature of these organizational units is that these organizational units have important links with universities and social institutions, through these organizational structures, universities will be upgraded. Communicate information and resources with the outside world can promote teacher-student entrepreneurial activities in colleges and universities.

MIT's corporate forums, entrepreneurship centers, technology entrepreneurship centers, Nanyang Technological University Enterprise Technology Transfer Office, Nanyang Science and Technology 
Entrepreneurs Center and other organizational units have integrated university resources to target entrepreneurship education and technological development, promote academic and knowledge use.

\subsection{Features of the organization operation method}

Unlike traditional universities, entrepreneurial universities not only have a variety of modes of operation such as classroom teaching and scientific research but also operate in ways that traditional universities do not have. Entrepreneurial entrepreneurs can directly participate in entrepreneurial activities and business operations. When research universities convert scientific research into practical applications or entrepreneurship, research universities have transformed into entrepreneurial universities [4]. The organizational goals of the entrepreneurial university are implemented in the consciousness of the organization personnel. Researchers or teachers and students identify business opportunities under the influence of relevant institutions and cultures, conduct business under conditions and conduct their own research results. They can apply to provide services to society and create value. MIT faculty, students, and alumni have created many businesses and created great economic value.

\subsection{Characteristics of organizational culture}

In traditional universities, the organizational culture of universities is characterized by academic development. The purpose of establishing a traditional university academic unit is to train scholars. Everyone pays more attention to the in-depth study of this topic and hopes to help the development of the subject knowledge system. Throughout the entire process, scholars are relatively loyal to the discipline. However, in entrepreneurial universities, the organizational culture is also expanding, emphasizing practical effectiveness and advocating the behavior of cooperation with university members in employment [5]. Through research, we found that the researchers of entrepreneurial universities are divided into traditional researchers engaged in basic research, researchers who focus on research topics, and researchers who specialize in technology development and technology use. In entrepreneurial universities, the members and organizations of the organization have changed the traditional way of development and paid more attention to the application of scientific research results.

In entrepreneurial universities, sound rules and regulations can promote innovation and entrepreneurship. These systems include the intellectual property system, the salary system for teachers and researchers, and so on. These systems have their own role. At the beginning of the 20th century, the Massachusetts Institute of Technology established a committee to study whether teachers are engaged in consulting services and developed the "one-fifth principle." Practice has proved that these institutional cultures can promote the stable development of entrepreneurial universities.

\section{Practice Paths of Entrepreneurial University}

\subsection{Pay attention to key aspects}

Perfecting the training mechanism of application-oriented entrepreneurship talents. Colleges and universities must adhere to the people-oriented teaching philosophy, reform colleges and universities personnel training model, pay attention to training students' practical ability. Colleges and universities should carry out personalized education for students, cultivate students' sense of innovation, innovation and professionalism, and integrate entrepreneurship education into vocational education [6]. In addition, colleges and universities also need to include innovation and entrepreneurship education curriculum groups, quality education, entrepreneurship science and technology competitions, and entrepreneurship team building into teaching activities, and improve students' overall quality in the teaching process. In order to adapt students to the society as soon as possible, colleges and universities need to reform their teaching content and curriculum system. In teaching, we must pay attention to training students' practical ability and innovation and entrepreneurship. 


\subsection{Build a flexible talent development system}

Colleges and universities need to reform the credit system, and on the basis of professional, curriculum, and teacher "three independent choices", continuously improve the teaching management system such as elective course management, credit certification, and reform the practice teaching and work practice, and the management methods of learning and semi-reading. Students can choose the pace of study, entrepreneurial practices etc. independently [7]. Some qualified colleges and universities can establish entrepreneurship education platforms in universities, such as the Zhejiang Institute for Entrepreneurship, and can establish entrepreneurial and employment bases for university students to improve their entrepreneurial abilities.

\subsection{Increase entrepreneurship training courses}

In order to improve the entrepreneurial ability of college students, colleges and universities need to establish a team of innovation and entrepreneurship education, mainly to study innovation and entrepreneurship education. Innovation and entrepreneurship education teams need to design scientifically innovative and entrepreneurial curriculum systems, study classroom teaching methods, and select appropriate teaching materials. Colleges and universities also need to provide some financial support. Qualified colleges and universities can set up entrepreneurship forums, innovative entrepreneurship courses, and can also open workplace training and entrepreneurship training courses. Students can learn business knowledge through these courses. In addition, universities can also strengthen cooperation with education and training groups and build a training platform.

\subsection{Reform the practical teaching mechanism}

In the process of innovation and entrepreneurship education, colleges and universities should pay attention to cultivating students' ability to innovate and improve the overall quality of students so as to train students as applied entrepreneurial talents [8]. Colleges and universities can build a business mentoring system to guide students in innovative entrepreneurial activities. In order to strengthen the exchange of innovative entrepreneurial experiences and information between teachers and students, colleges and universities can also build entrepreneurial information exchange platforms, entrepreneurial achievement display platforms, etc. to enhance communication between teachers and students. Universities can also integrate innovation and entrepreneurship education into teaching and extra-curricular activities through school-enterprise cooperation, school simulation training, student community activities, and holiday social practices. This will effectively enhance college students' practical ability and innovation and entrepreneurship.

\subsection{Establish an entrepreneurial teacher team}

In order to build an entrepreneurial university, colleges and universities should improve the teacher management system, and actively introduce and train a large number of innovative entrepreneurship education personnel. At present, there are still problems in the lack of professional entrepreneurial teachers in colleges and universities in China. Therefore, colleges and universities should cultivate entrepreneurial teachers and establish professional entrepreneurial teachers [9]. In addition, colleges and universities also need to strengthen communication with local scientific and technological talents. In order to strengthen entrepreneurship education, colleges and universities can employ some experts or entrepreneurs to teach in colleges or universities or hire some high-level talents to come to colleges and universities to serve as mentors and enhance related courses' effectiveness. Colleges and universities need to constantly reform the teacher training system and adopt cooperative methods such as attracting enterprises to enter colleges, transfer education, and other enterprises, and establish dual-qualified teachers team with rich experience.

\subsection{Establish an entrepreneurial base and fund}

Colleges and universities need to build a teacher-student entrepreneurship base and college students' business start-up base. Through the construction of entrepreneurship practice slips and entrepreneurship training, teachers and students can increase their entrepreneurial ability. Colleges 
and universities also need to set up venture funds together with local governments, cooperative enterprises, etc. to guide students in innovation and entrepreneurship activities, inspire students' awareness of innovation and entrepreneurship, and cultivate science and technology entrepreneurs. In addition, universities should also build innovative training platforms, formulate fund management systems, and strengthen the use and management of venture capital funds.

\subsection{Build a campus entrepreneurial culture atmosphere}

Use the entrepreneurial culture to promote the stable development of various undertakings in colleges and universities. In simple terms, entrepreneurial culture is a spiritual force that encourages people to create and pursue a better life. It is a courageous and forward-looking cultural form. Entrepreneurial culture is of great significance to the establishment of entrepreneurial universities. When building an entrepreneurial university, an entrepreneurial campus culture atmosphere should be built [10]. Using the methods of media propaganda, improving the system, and carrying out activities, etc., the role of entrepreneurial culture can be brought into play so that entrepreneurial universities can always be in a positive state.

\section{Summary}

In short, entrepreneurial universities have two different forms, one is "innovative" university, and the other is "leadership" university. Although these two universities have some common points, such as: pay attention to the transformation of scientific research results, but the two have different goals in the organization, organization and other aspects. The research in this article is mainly conducted in the sense of "leadership" entrepreneurial university.The establishment of an entrepreneurial university is a long-term and systematic project, including the undergraduate talent training mechanism, the establishment of an entrepreneurial teacher team, and the enrichment of the entrepreneurial practice mechanism.

\section{References}

[1] Li Jin. Research on the Connotation Evolution and Influencing Factors of Entrepreneurial Orientation[J]. Enterprise Herald, 2016(2):139-140.

[2] Yingnan Dong. Research on Spatial Knowledge Spillover of Academic Entrepreneurship [D]. Dalian University of Technology, 2016.

[3] Yujuan Han. Research on the Influence of Social Entrepreneurial Orientation on Organizational Innovation[D]. Dongbei University of Finance and Economics, 2016.

[4] Jiade Zhu. Analysis on the Organizational Characteristics of Colleges and Universities' Entrepreneurial Colleges_—Based on the Empirical Data of the First Demonstration Universities to Deepen Innovation and Entrepreneurship Education Reform[J]. China Higher Education Research, 2017(11):49-53.

[5] Xinghong Tian, Yonghua Zhang, Qiongying Xiao, et al. Structural Characteristics and Connotation Analysis of Undergraduate Teaching Quality Assurance System in Local Colleges of Science and Technology_-Mainly Based on The Quality Assurance System of Undergraduate Teaching in Changsha University of Science and Technology [J]. Education in Innovation and Entrepreneurship, 2017, 8(1):129-133.

[6] Haijun Wang, Rensun Ye, Jianqiong Wang. Research on the Conceptual Model of Public Entrepreneurial Path Selection Structure[J]. Journal of Educational Monthly, 2017(10):22-30.

[7] Wenhong Cao. Analysis of Youth Entrepreneurship under the Background of "Double Creation" [J]. Chinese Youth Studies, 2016(4):5-9.

[8] Lingbin Kong. Research on the Influencing Factors of College Students' Intention to Entrepreneurialism[J]. Science \& Technology and Enterprises, 2016(9):177-177. 